\title{
The Effect of Peer-Led Review on Exam Performance in Fluid Mechanics
}

Dr. Thomas Shepard, University of St. Thomas 


\section{The Effect of Peer-Led Review on Exam Performance in Fluid Mechanics}

This paper discusses the use of peer-led review in an introductory fluid mechanics course over multiple semesters. In the peer-led review small teams of students presented a review of material to the entire class from a specific chapter prior to an exam. The material to be presented was examined by the instructor prior to the review to ensure accuracy and completeness in the coverage. Specific questions on each of the three course exams were written to test knowledge of material specifically reviewed by each peer team. By comparing the performance of the members of a review team with those of the rest of the class on these questions a comparison could be made to gauge how the act of leading one's peers in a review of material affects one's knowledge in a given area. Additionally, a student's exam performance was compared on questions relating to chapters which they led a review versus all other questions. It was found that $76 \%$ of students saw an increase in performance on questions relating to chapters on which they led a review as compared with all other chapters. Those students who saw an increase in performance had an average increase of $14 \%$ while the population wide increase was over $8 \%$ showing that participating in the exercise had a net positive effect. This paper discusses these results further as well as the survey results used to gather student impressions on the experience and impact of leading an in-class review of material for one's peers.

\section{Introduction}

Complex engineering knowledge and skills can sometimes be difficult to learn in a lecture format from a single instructor. This is due to the fact that the material is presented in a way which makes the most sense to the instructor, though it may not be as clear to the student. As the instructor has likely studied the subject in-depth and taught it many times it can be difficult for them to recall what was confusing to them when they learned it the first time, while the students in the course can be keenly aware of where confusion is arising. Peer tutoring is a practice which takes advantage of this to improve student learning by having students learn from other students. It is important to note that peer tutoring can be accomplished in a variety of ways and Topping ${ }^{1}$ identifies ten dimensions which can be varied depending on the specific implementation used:

1. curriculum content covered by peer tutors

2. number of tutors and tutees

3. tutor and tutee year(s) of study - tutors could be from same year of study or be more advanced

4. tutor ability relative to tutee ability - tutors could have similar or superior ability as average student

5. role continuity - the tutor and tutee may sometimes switch roles

6. place of tutoring

7. time dedicated to tutoring

8. tutee characteristics - all students, at-risk students, gifted students, etc.

9. tutor characteristics

10. objectives - intellectual gains, attitudinal gains, increased retention, etc. 
In its most basic sense, peer tutoring can go by many names. Collaborative learning, cooperative learning, peer assisted learning and peer instruction are some common examples. Peer tutoring can take many formats which vary significantly in the amount of time and training required from the instructor and participants. Some peer tutoring activities which are described in science and engineering literature include:

- $\quad$ peer mentoring programs where trained students hold office hours ${ }^{2}$

- peer mentoring programs where trained students assist in class and lab ${ }^{3-4}$

- $\quad$ peer led team learning workshops guided by an advanced undergraduate student who has received training ${ }^{5}$

- peer instruction during lecture where students first answer a conceptual question individually and then discuss the problem in a small group ${ }^{6-7}$

- think-pair-share - like peer instruction but not constrained to conceptual questions ${ }^{8-10}$

Results from these experiences, and many others, consistently show a benefit for both the student doing the teaching and the student learning from their peer ${ }^{1}$. McKeachie and Svinicki ${ }^{10}$ also report that learning is increased by peer tutoring for the majority of students and does not hurt the learning of the others.

The act of teaching as part of the peer tutoring process plays a large role in student learning. Joseph Joubert is credited with the quote "to teach is to learn twice" which aptly summarizes what many instructors have already experienced. When students are asked to take responsibility for teaching their peers the student must learn the subject well enough to present it and the peers being taught get the valuable experience of seeing the material presented multiple ways. The act of preparing to teach can require students to:

- $\quad$ structure their thoughts

- provide explanations

- communicate technical content

- demonstrate problem-solving techniques

- interact with others, often as part of a team or small group thus developing interpersonal skills

- develop higher-level questions as students need to admit confusion

- study material more deeply

- increase their ownership over learning the material

These activities and behaviors are beneficial to student learning and can be neglected in a traditional lecture format. This paper discusses the use of a peer-led review as a method of peer tutoring in which small teams of students were assigned to lead reviews of different chapters in fluid mechanics. This peer tutoring activity is similar to the team "learning syndicate" described by McKeachie and Svinicki ${ }^{10}$. Two opportunities for peer tutoring can be captured in this single assignment. The first was within the small team as it prepares material for its review session. The second is when the team actually delivers its review session to their classmates (i.e. teaches).

In order to complete the assignment the small team of students had to meet to discuss the different topics and divide material. The initial small group discussions facilitate both the transmission of knowledge from the stronger students as well as the co-construction of 
knowledge when the group talks through questions and confusing topics. Smith et al. have documented these two modes of improving conceptual understanding through peer tutoring ${ }^{11}$. The importance of this small group is further stated by McKeachie and Svinick ${ }^{10}$ : "Students are more likely to talk in small groups than in large ones; students who are confused are more likely to ask other students questions about their difficulties or failure to understand than to reveal these problems with a faculty member present. Students who are not confused must actively organize and reorganize their own learning in order to explain it. Thus both the confused and the unconfused benefit."

The team was also required to meet with the course instructor to share their materials and discuss what the team was presenting. This allowed any lingering misconceptions to be discussed and served as a quality control over the content that was delivered in the classroom. Knowing that they had to teach the material forced a student to overcome their confusion. If one student is able to articulate their misconception and then work through it to gain a complete understanding they can better help to clear up others' misconceptions as they better relate to how the misconception occurred. The fact that material was approved beforehand also allows students in the class to trust the information being presented, despite the fact that it is coming from their peers instead of a professional teacher. Due to the abstract and mathematical nature of fluid mechanics it was imperative that the information delivered by the team be accurate and that it seem credible.

The activity had participation from 70 students in three sections of an introductory fluid mechanics course. Small teams of students were assigned to lead a class-wide review of a chapter prior to an exam. Student performance on the exams was analyzed to determine how the act of leading a review affected a student's score on questions covering material from different chapters. Details of the peer-led review assignment, student feedback from the experience, lessons learned and project results are discussed.

\section{Peer-Led Review Activity}

Students were made aware of this assignment on the first day of class while discussing the syllabus; teams, topics and review dates were determined by the end of the first week once the class roster had more stability. The goal of making students aware of which chapter and date they would be reviewing early was to allow students to start preparing early. Teams typically consisted of 4-5 students and each team was given a single chapter for which to develop a review that would be presented in class. In addition to some primary goals, the peer-tutoring aspect of the assignment is also believed to engage higher level of student learning on content in the fluid mechanics course.

The primary objectives as described to the students were to practice and develop the following engineering skills:

- working as part of a team

- orally presenting material

- engineering communication

- critical analysis of mistakes that can be made 
- critical analysis of assumptions that can be made

Students were provided a list of important topics from each chapter and instructed to determine how best to distill and review the relevant material. Both conceptual and quantitative topics were listed as important. As part of the review each group had to develop at least one review problem, similar to something one might expect on a test. This problem could not come from any of the course materials (homework problems, in-class examples, textbook) and required a handout for student use during the review. The solution was presented as part of the review following a clear problem solving approach with particular attention paid to:

- reasons for following the process that they used (how would one know to use formulas/relations used, etc.)

- assumptions made (why make them, how to justify them, how they affect the solution, etc.)

- potentially easy mistakes that could have been made (unit conversions, table confusion, use of unjustifiable assumptions, etc.)

- physical meaning of the answer

Each group was allotted 32 minutes to present their review and problem solution(s) and each group member was required to present some material. Typically, two groups presented during a 65 minute class period shortly before one of the three large exams in the course ( 2 midterms and final). To avoid rushing, a group was allowed to focus on certain material during their presentation at the expense of cutting out other important topics from their review chapter. This was allowed only if the group created a review sheet handout for the important material not presented during the review. Students were instructed to present in the manner they thought would be best (lecture, power point, handouts, videos, demonstrations, etc.). Students were encouraged to expend significant effort in thinking about how best to present each part in a way that would make sense to the other students in the class and create as little confusion as possible. Teams were also required to interact with the audience at least twice during their presentation in whatever manner they saw fit. Reviews which built off of, or incorporated, material from other chapters were also encouraged. To ensure accuracy and proper scope, all problems, solutions, PowerPoint slides and notes were approved by the instructor at least one day before the review was presented.

The instructor made clear that the goal for a team's review was to help the students in the class understand the relevant material, not to reinvent the wheel. If there was a resource available that was useful, students were encouraged to find it and use it (with proper citation). The instructor made additional textbooks available and was available to meet or watch a test-run in order to provide feedback.

The peer-led review assignment counted as $10 \%$ of student's overall grade for the course. An individual student received a grade for the review based on three components:

- Individual grade (50\%) - instructor assessed clarity, thoroughness and correctness of an individual's part of the presentation

- Group grade (25\%) - instructor assessed clarity, thoroughness, flow and correctness of entire presentation 
- Team member assessment (25\%) -teammates graded each other on the ability to work in a team and contribute to the group's effort

The goal of this grading structure was to have students hold their teammates accountable for contributing while balancing the negative impact that a single teammate who presented poorly would have on the other team members' grades.

\section{Peer-led Review Format}

In the three different class sections a total of 70 students took part in developing and presenting a review. A total of 14 teams led reviews. The format that most teams settled on took the following structure:

- lecture on some concepts using PowerPoint and asking the audience questions

- present a simple example problem utilizing some of the concepts just discussed

- give students some time to work the problem

- quickly go over problem solution

- lecture on some more concepts using PowerPoint and asking the audience questions

- present a complex example problem utilizing some of the concepts just discussed

- give students some time to work the problem

- quickly go over problem solution

Some examples of shorter problems presented by students during the review include the following:

Assume that there is a wind blowing at $8 \mathrm{~m} / \mathrm{s}$ and a Hummer is traveling at $32 \mathrm{~m} / \mathrm{s}$.

a) How much power is used to oppose the drag force when driving with the wind?

b) How much power is used to oppose the drag force when driving against the wind?

Your dog sticks his head out of your car window when you are driving $35 \mathrm{mph}$. What is the maximum pressure on his nose? (assume STP conditions)

Some examples of longer problems presented by students during the review include the following:

The brothers of Phi Gamma Delta are looking for a way to drain the pool on their second story porch. They decide the only logical solution is to create a pipe system from their pool to a Slip n' Slide located $500 \mathrm{ft}$. from their house. The pool is located $30 \mathrm{ft}$. above the ground and the piping system looks as below (not shown). Assuming fully developed flow, what is the flow rate at the Slip n' Slide?

The largest free flying U.S. flag was set up in New Jersey and measured 60 feet tall by 114 feet long. If this flag was flown on a 75 foot antenna on the top of the Empire State Building, estimate the additional torque which must be withstood by the building's foundation. 
This format is remarkably similar to how the instructor presents material in lecture. However there were a few key differences. These involved the increased use of PowerPoint compared to lecture, the reduced amount of time students were given to work an example problem by themselves and how quickly the problem solution was presented. These differences were likely done in the interest of time. Conceptual topics could be covered more quickly by not having to write on the board and instead having a prepared PowerPoint slide. The reduced time on problems was the result of a couple factors. The 32 minutes was strictly enforced and teams often tried to cover everything as opposed to picking some topics on which to focus. It is likely that some teams did not adequately practice their presentation to fully understand its timing. Also, a few presenters may have taken more time when in front of the class than when practicing. Finally, a few groups made some unapproved additions and covered material which was not relevant for their review. As it would have been awkward to interrupt the student the instructor simply let the extraneous material be presented, which took time away from the example problems.

In general the presentations covered $\sim 95 \%$ of the material that the instructor would have covered but showed it to the class in a slightly different format than they had originally seen it from the instructor. The level of detail and accuracy were adequate thanks in part to instructor feedback on review materials prior to their presentation. If a student did make an inaccurate statement during their presentation the instructor would politely correct them. Typically the inaccurate statements were a simple oversight and not due to confusion on the student's part. They were often able to correct themselves simply by hearing the instructor repeat their statement back to them. A small number of students had poor eye contact, were monotone, or talked to the white board instead of projecting to the class. This was to be expected and the students were provided feedback so that their future presentations could be improved. For the majority of teams, the overall the quality of the student-led reviews was believed to be roughly equivalent to an instructor-led review. A few teams had a single teammate whose portion was inadequate which meant that part of the presentation suffered. Due to the fact that their part was just a fraction of the overall review, the experience would still have had a net positive effect as a review.

In addition to the basic format described above there were many groups that incorporated unique features into their reviews. Candy was commonly used to reward students who answered questions posed to the class. Brief conceptual quizzes were presented by some teams (Fig. 1) throughout their review. Videos, or more specifically Youtube videos that had not been shown in class, were used to demonstrate concepts acting in the real world. To demonstrate relative velocity one reviewer asked a participant to stand up and walk next to him. From his perspective the other student did not have a velocity when they walked at the same speed. One team developed a small group challenge where teams were given a sheet of paper, a drinking straw and a ping pong ball and asked to determine a way to propel the ball to a maximum height. At the end of the exercise the group described how Bernoulli's principle was involved in the winning team's method. As a way to start their review, one team asked the class to stand up and do some brief calisthenics to get their blood pumping and ready to review. A fantastic analogy from one group discussed how laminar vs. turbulent flows were analogous to classical vs. death metal music. Density differences and buoyancy were demonstrated with mixtures of different immiscible liquids. The principles of the ideal gas law and pressure were demonstrated through use of hot and cold water causing a plastic bottle to crumple. Some teams also developed 
extremely clean/organized handouts for solving dimensional analysis problems or Navier-Stokes problems where there was a spot to list assumptions, equations, variables, and procedure steps were defined. The project clearly allowed for student creativity which was demonstrated by a surprisingly large number of teams.

\section{Moody's Chart Quiz!}

1) What are the two factors which Moody's Chart is based on?

Answer: $\operatorname{Re} \& \frac{\varepsilon}{D}$

2) What forces is Reynolds number qualitatively a ratio of?

Answer: Inertial forces ( $\rho v d)$ over viscous forces $(\mu)$

3) Is friction factor used in major losses, or minor losses?

Answer: Major Losses

4) Once our flow reaches wholly turbulent, what is $f$ ONLY

dependent on?

Answer: $\frac{\varepsilon}{D}$

Figure 1. Example quiz of conceptual concepts from a student-led review

\section{Assessment}

In each course that the student-led review was assigned there were three large exams: two midterms and a final. Exams included both conceptual and quantitative problems and were comprehensive in nature, however many questions involved material from a single chapter. Any question which required utilization of knowledge from multiple chapters (i.e. Bernoulli problem which uses a U-tube manometer to measure pressure difference) was not considered for the analyses in this study. A total of 18-20 test questions were used each semester to compare student comprehension on material for which they led a review vs. other material. Two different analyses were done on the test data from each course. In one analysis a students' performance on questions from the chapter they reviewed was compared to their performance on questions from all other chapters. In the other analysis the average performance by a review team on a test question specific to their chapter was compared to the average performance of the rest of the class on that same question.

The results show that $76 \%$ of the students scored higher on exam questions on chapters for which their team led a review than questions from other chapters. This result takes into account all chapters which were covered in the class. The average increase in performance was $14 \%$, meaning that the student would have earned 14\% more of the available points on questions from the chapter they reviewed than other questions. The maximum increase was $32 \%$. Of the $24 \%$ of students who scored lower on material which they reviewed, the average decrease in performance was $7 \%$. The maximum decrease was $16 \%$. When accounting for all students in this study, an $8 \%$ increase in performance is found on material which their team reviewed. It is concluded that there is a significant net positive effect which results from students participating in the peer-led review on exam performance for the students leading the review. 
The results further show that the average score on a single question was greater for the members of the review team than the average score for the rest of the class on $75 \%$ of the questions examined in this study. It is believed that this result would be higher if greater care had been taken in creating teams of equal academic aptitude. Though some students showed a decrease in exam performance they will have had the additional benefits practice stated in the original project objectives (i.e. working in a team, engineering communication, etc.). No clear trends regarding were observed in comparing exam performance for teams which reviewed early chapters vs. later chapters.

A post-project survey of the students was used to gather feedback. Table 1 shows the seven statements that students were presented, as well as a break-down of student responses and the average response to each question. A Likert scale was used, and the percentage of students that responded to a given scale (1-5) is presented in parentheses for each statement. For example, on statement $152 \%$ of students agreed with the statement and $27 \%$ strongly agreed.

Table 1. Post-project survey and results

\begin{tabular}{|c|c|c|c|c|c|c|}
\hline & $\begin{array}{l}\text { strongly } \\
\text { disagree }\end{array}$ & disagree & neutral & agree & $\begin{array}{c}\text { strongly } \\
\text { agree }\end{array}$ & $\begin{array}{c}\text { Avg. } \\
\text { response }\end{array}$ \\
\hline $\begin{array}{l}\text { 1. Participating in the review forced me to learn } \\
\text { the material I presented better than I would have if } \\
\text { I had no presentation. }\end{array}$ & $\begin{array}{c}1 \\
(\mathbf{0})\end{array}$ & $\begin{array}{c}2 \\
(1)\end{array}$ & $\begin{array}{c}3 \\
(20)\end{array}$ & $\begin{array}{c}4 \\
(52)\end{array}$ & $\begin{array}{c}5 \\
(27)\end{array}$ & 4.1 \\
\hline $\begin{array}{l}\text { 2. Learning from my peers was beneficial to my } \\
\text { learning. }\end{array}$ & $\begin{array}{c}1 \\
\text { (1) }\end{array}$ & $\begin{array}{c}2 \\
(4)\end{array}$ & $\begin{array}{c}3 \\
(38)\end{array}$ & $\begin{array}{c}4 \\
(51)\end{array}$ & $\begin{array}{l}5 \\
(\mathbf{5})\end{array}$ & 3.5 \\
\hline $\begin{array}{l}\text { 3. I was too nervous on my presentation day to } \\
\text { learn from the other group which presented that } \\
\text { day. }\end{array}$ & $\begin{array}{c}1 \\
(25)\end{array}$ & $\begin{array}{c}2 \\
(38)\end{array}$ & $\begin{array}{c}3 \\
(29)\end{array}$ & $\begin{array}{c}4 \\
(6)\end{array}$ & $\begin{array}{l}5 \\
(1)\end{array}$ & 2.2 \\
\hline 4. I took notes on what other students presented. & $\begin{array}{c}1 \\
\text { (0) }\end{array}$ & $\begin{array}{c}\mathbf{2} \\
(\mathbf{5})\end{array}$ & $\begin{array}{c}3 \\
(25)\end{array}$ & $\begin{array}{c}4 \\
(45)\end{array}$ & $\begin{array}{c}5 \\
(25)\end{array}$ & 3.9 \\
\hline $\begin{array}{l}\text { 5. I focused on my section of material at the } \\
\text { expense of not spending enough time on other } \\
\text { material. }\end{array}$ & $\begin{array}{c}1 \\
(4)\end{array}$ & $\begin{array}{c}2 \\
(12)\end{array}$ & $\begin{array}{c}3 \\
(26)\end{array}$ & $\begin{array}{c}4 \\
(41)\end{array}$ & $\begin{array}{c}\mathbf{5} \\
(\mathbf{1 7})\end{array}$ & 3.6 \\
\hline $\begin{array}{l}\text { 6. I spent less time reviewing for the test outside } \\
\text { of class because of how much time was spent in } \\
\text { class. }\end{array}$ & $\begin{array}{c}1 \\
(\mathbf{5})\end{array}$ & $\begin{array}{c}2 \\
(45)\end{array}$ & $\begin{array}{c}3 \\
(26)\end{array}$ & $\begin{array}{c}4 \\
(21)\end{array}$ & $\begin{array}{l}5 \\
\mathbf{( 3 )}\end{array}$ & 2.7 \\
\hline $\begin{array}{l}\text { 7. Overall the student lead review was a } \\
\text { worthwhile experience. }\end{array}$ & $\begin{array}{c}\mathbf{1} \\
\text { (1) }\end{array}$ & $\begin{array}{c}2 \\
\mathbf{( 0 )}\end{array}$ & $\begin{array}{c}3 \\
(26)\end{array}$ & $\begin{array}{c}4 \\
(55)\end{array}$ & $\begin{array}{c}5 \\
(18)\end{array}$ & 3.9 \\
\hline
\end{tabular}

The student responses to statements 1,2 and 7 show that the students viewed the experience as worthwhile and one that improved their knowledge of the course material over what they might get from simply having the instructor lead a review. This is important because no extra class time was required to have this gain; lecture time would have been dedicated to a review even if the instructor was conducting it. One concern of the author prior to the project involved the fact 
that two reviews occurred during a single class period. Thus, if a student was too nervous about public speaking they might not have taken anything away from a review that happen directly before or after theirs. However, only $7 \%$ of students agreed that their nerves got in the way of their learning. Another concern in approaching the project was that students would reduce the amount of time they spent reviewing material outside of class based on the in-class reviews. The results show that $76 \%$ of the students did not agree with this. The survey results do expose one possible area of improvement in that a significant number of respondents (58\%) agreed that they focused solely on their part of the review and thus may not have learned the other material from that chapter as well. This was cited in the open-ended questions on the survey as well which found the following responses:

What could I have done as a student to get more out of the project?

- don't focus solely on my subsection of the chapter

- taken better notes throughout the semester to better prepare

- $\quad$ spent more time with my team

- prepared sooner

- taken better notes during other student presentations

- practiced our review more

- written a problem myself rather than finding one in another textbook

- used more multi-media during presentation (i.e. mix things up)

What suggestions do you have for improving the project?

- more practice problems that display key concepts (repeated frequently)

- allow for longer presentations so that more material can be covered while being less rushed (repeated frequently)

- find a way to get students to prepare like they are going to present any part of the review so they don't just focus on their section

- have review at end of chapter rather than right before exam

- have groups hand out notes and solutions afterwards

- encourage more/better interaction with audience

- provide more help finding example problems

- none - it was a good way of meeting new people

Working in teams can often present a problem on engineering projects. The results from this assignment show minimal conflict caused by team members not pulling their weight. A review of the peer assessments showed that $90 \%$ of teammates were rated as contributing equal amounts during the process, $7 \%$ were rated as contributing less than their teammates and $3 \%$ were rated as contributing more than their teammates. It is noted that the team sizes could be kept to a manageable 4-5 students as the class sizes ranged from 21-25 students. 


\section{Suggestions for Improvement}

There are three major improvements that are suggested for future implementations of this project. The 32 minute window for presenting was a little too short for what the students tried to cover. Though students were told that they could leave important material out of their presentation most teams did not do this resulting in parts of the review feeling rushed. One potential solution would be to explicitly give the students less material to cover which the instructor could then present at some other time. Alternatively, if the student-led reviews were given 45-50 minutes out of a 65 minute lecture the students would be less rushed and the final minutes of class could be used by the instructor to correct any mistakes or fill in any gaps from the review.

Quality control is a critical for the success of this assignment. Many teams were found to procrastinate to the detriment of their review when they did not leave time for adequate instructor feedback. Procrastination also led to some teams spending lots of time just before presenting to develop a problem, only to learn that their problem was incorrect. In the future it is suggested that the team meet with the instructor two weeks prior to the review and be required to turn in a short report stating what they are planning to do, who will be doing what, and when the group will be meeting. It would also be useful for the instructor to meet with the team in the last minutes of class roughly a week before the presentation to answer any questions and remind them of available office hours for further discussion. Requiring materials to be turned in 24 hours before the review was too short of a window for some teams who needed extensive revisions. It is recommended that teams be required to turn in their materials 4-5 days prior to their presentation. It is also recommended that teams be required to give a practice review in front of the instructor. This would allow for greater control over both the accuracy and breadth of content, as well as provide feedback on delivery to improve multiple aspects of their in-class review.

The issue of students focusing on a subsection of their review chapter is also troubling. There is certainly a logic to the "divide and conquer" approach to a big project, yet that takes away from some of the peer-tutoring which this project hopes to elicit. One way around this would be to break the review into specific sections, for example: concepts 1 , problem 1, concepts 2 , problem 2. Students seem to naturally arrive at this structure anyway, so dictating this structure to them would likely not face much push-back. To ensure that students were fully informed on each section the instructor could randomly assign team members to the different presentation sections on the morning of the in-class review. Students could still divide and conquer when developing their review in this scenario. However, each student would essentially need to teach their material to the group so that any group member could present any section. This would create slightly more work for the team and could face some criticism. It is suggested that by explaining the logic of this format to the students this criticism will be reduced, though probably not eliminated.

\section{Conclusion}

This paper describes a peer-tutoring exercise where small groups of students develop and deliver a review in a fluid mechanics course. The purpose of the peer-led review was not to save the 
instructor time spent developing review material, but rather to promote student learning of course material while obtaining practice in working as part of a team and orally presenting technical content. The act of preparing and delivering a review was shown to increase student performance on test questions. Feedback from the project demonstrates that students also think the activity is beneficial which provides strong support for its inclusion in future classes whose class size allows for appropriate team sizing. Future improvements to the project involve a more structured oversight of review quality, extended time for presentations and randomized assignments to force all team members to understand all parts of their review. Though teams were formed by randomly assigning students, the feedback demonstrates that teamwork difficulties were relatively small. An opportunity might exist for improving the project by specifically dividing the students into teams which equally account for the range of student ability. This would ensure that teams have brighter students who could help teach confusing material to their teammates before the review, thus increasing the opportunity for peer-teaching gains in content knowledge. However, this would require the instructor to have some metric of student academic aptitude coming into the course. This could be done using a first day survey, or student transcripts, but must be viewed with caution as success in previous courses does not necessarily mean that a student will have the same success in fluid mechanics.

It is believed that keeping the team size to 4-6 students is important for keeping all students engaged in the development and delivery of a review. In smaller class sizes this can be done quite easily but could be a challenge for larger classes. Though, for large courses which have multiple smaller recitation sections the review could be delivered in such a setting. If smaller recitation sections are not available the assignment could be used as a way to have student teams prepare a review which would not actually be presented (i.e. as a small team prepare a review that you would present if course time permitted). The peer teaching could still take place in the small groups. While the class-wide teaching of one's peers might not happen, the instructor could still present parts of the student prepared reviews which could allow for students to see material from an alternative perspective. However, it is believed that actually having the students deliver the material will lead to the strongest effect as they will likely spend more time mastering it in preparation for having to actually teach. It also forces the peer teaching to take place as a student cannot be passively engaged when they know they will be presenting material. Alternatively, a large class could use other forms of peer teaching during lecture-based review periods such as think-pair-share, peer instruction, etc.

Through its implementation in three courses the described project has been shown to spur student creativity and has developed resources that the instructor can use in future classes. After struggling through their review unexpectedly one student commented to the instructor:

"Did you just have us do this so that we would better appreciate how hard it is to teach?"

While this was not an intended objective of the project, it is nice to see that some students gain a better appreciation for their teachers as a result. 


\section{References}

[1] Topping, K.J., (1996). The Effectiveness of Peer Tutoring in Further and Higher Education: A Typology and Review of the Literature, Higher Education, 32(3), pp. 321-345.

[2] Kirkham, R. and Hingelstein, D., (2008). Student Peer Assisted Mentoring (SPAM): A Conceptual Framework, E-journal of Business Education and Scholarship Training, 2(2), pp. 39-49.

[3] Jaeger, B.K., Blaint, C., Wishon, C. and Fritze, C., (2010). ATLAS - Academic Teaching and Learning Assistants Study: The Use of Peers as 'Quality Managers' in Engineering Class Instruction, Proceedings of the 2010 ASEE Annual Conference, Louisville, KY, AC 2010-1298.

[4] Jaeger, B.K., Liss, K., van den Heuvel, B. and Wilson, E., (2013). Those who can, teach. Immersiting Students as Peer Educators to Enhance Class Experience, Proceedings of the 2013 ASEE Annual Conference, Atlanta, GA, Paper 6753.

[5] Flores, B., Becvar, J., Darnell, A., Knaust, H., Lopez, J. and Tinajero, J., (2010). Implementing Peer Led Team Learning in Gateway Science and Mathematics Courses for Engineering Majors, Proceedings of the 2010 ASEE Annual Conference, Louisville, KY, AC 2010-1659.

[6] Crouch, C.H. and Mazur, E., (2001). Peer Instruction: Ten years of experience and results, American Journal of Physics, 69, pp. 970-977.

[7] Brooks, B. and Koretsky, M., (2010). The Effect of Peer Instruction on Students' Construction of Conceptual Understanding in Thermodynamics, Proceedings of the 2010 ASEE Annual Conference, Louisville, KY, AC 20101929.

[8] Gehringer, E.F., (2007). Active and Collaborative Learning Strategies for Teaching Computing, Proceedings of the 2007 ASEE Annual Conference, Honolulu, HI, AC 2007-2328.

[9] Holzer, S.M. and Andruet, R.H., (1998). Learning Statics with Multimedia and Other Tools, Proceedings of the 1998 ASEE Annual Conference, Seattle, WA, Session 1658.

[10] McKeachie, W.J. and Svinicki, M., (2006). Teaching Tips, Stategies, Research, and Theory for College and University Teachers, Houghton Mifflin, Boston, MA.

[11] Smith, M.K., Wood, W.B., Adams, W.K., Wieman, C., Knight, J.K., Guild, N. and Su, T.T., (2009). Why peer discussion improves student performance on in-class concept questions, Science, 323(5910), pp. 122-124. 